\title{
Bovine trypanosomosis and gastrointestinal helminthosis in settlement villages of Bedele district, South-western Ethiopia
}

\author{
Moti Yohannes ${ }^{1}$, Derara Birasa ${ }^{l}$, Dalasa Damena ${ }^{2}$, Senbeta Tasew ${ }^{3}$ and Hailu Degefu ${ }^{l} *$ \\ ${ }^{\prime}$ Jimma University, College of Agriculture and Veterinary Medicine, P.O.Box 307, Jimma, \\ Ethiopia \\ ${ }^{2}$ National Animal Health Diagnostic and Investigation Center, Molecular Diagnostic \\ Laboratory, P.O.Box 04, Sebeta, Ethiopia \\ ${ }^{3}$ National Tsetse and Trypanosomosis Investigation and Control Center, P.O.Box 113, \\ Bedelle, Ethiopia \\ *Corresponding Author:E-mail: hailu.degefu@ju.edu.et
}

\section{Abstract}

This cross-sectional study was carried out from October 2011 to March 2012 to assess the concurrent infections of bovine trypanosomosis with gastrointestinal (GI) helminthes in Peasant Associations of Bedele district settlement areas located in Illubabor Zone, Southwestern part of Ethiopia. A total of 500 randomly selected cattle were examined using Buffy Coat Technique and coprological examinations. Faecal examination was done by sedimentation and flotation techniques following the standard procedures to identify eggs of parasitic helminthes. Those faecal samples that were positive for flotation technique were subjected to eggs per gram (EPG) count using Mc Master egg counting technique and the degree of infestation was categorized as light, moderate and severe. Out of total cattle examined, 21(4.2\%) were positive for Trypanosoma congolense and 321(64.2\%) were found to harbor one or more gastrointestinal helminthes infection. Helminthes identified were Fasciola species $(51.4 \%)$, paramphistomum species $(18.7 \%)$, the protozoan Eimeria species $(6.2 \%)$, Trichuris species (6.85\%), Trichostrongyles $(11 \%)$ and mixed infections (6\%). The overall mean PCV value recorded was $26.7 \pm 3.9$ and it was $26.8 \pm 3.9$ in trypanosome negative animals and $22.9 \pm 3.3$ in trypanosome positive animals. The overall mean EPG recorded was 172 \pm 99.6 . Among 21 cattle found positive for $T$. congolense, $18(85.7 \%)$ were concurrently infected with (GI) helminthes particularly Fasciolosis (38.1\%) and statistically there was significant association $(\mathrm{P}<0.05)$ between trypanososmosis and GI helminthes infection. Age and sex of sampled cattle were not found to influence GI helminthes prevalence $(\mathrm{p}>0.05)$. Infection with $T$. congolense and Fasciola species is the most prevalent form of co-infection in cattle within study areas. In conclusion, any attempts to control or prevent trypanosomosis or GI helminthes infection through different management approaches, need to address the possibility of concurrent infections especially in trypanosomosis endemic areas to save the losses in advance.

Key words: Bedele, Cattle, Concurrent, Ethiopia, GI helminthes, Trypanosomosis

http://dx.doi.org/10.4314/evj.v17i1.4 


\section{Introduction}

African animal trypanosomiasis (AAT) is a parasitic disease that causes serious economic losses in livestock from anemia, loss of condition and emaciation. Many untreated cases are fatal. AAT is found mainly in those regions of Africa where its biological vector, tsetse fly, exists (CFSPH, 2009). Among animal diseases, bovine trypanosomiasis continued to be the major constraints of livestock production in Sub-Saharan Africa, jeopardizing the lives of 55 million people. The risk of infection in humans as well as in domestic animals has greatly affected social, economical and agricultural development of communities within tsetse infested areas which roughly constitutes more than a third $\left(10\right.$ million $\left.\mathrm{km}^{2}\right)$ of Africa between $14^{\circ} \mathrm{N}$ and $29^{\circ} \mathrm{S}$ of the continent (FAO, 2002; Radostitis et al., 2000). In Ethiopia, six species of trypanosomes are recorded and the most important trypanosomes in terms of economic loss in domestic livestock are tsetse transmitted species: T.congolense, T.vivax and T. brucei (Getachew Abebe, 2005).

In addition, helminthes infections are important causes of productivity loss in livestock worldwide (Vercruysse and Claerbout, 2001). Moreover, gastrointestinal (GIT) helminthes infections concurrent with bovine trypanosomosis is also a worldwide problem for both small- and large-scale farmers, but their impact is greater in sub-Saharan Africa in general and Ethiopia in particular due to the availability of a wide range of agro-ecological factors suitable for diversified hosts and parasite species. Among gasterointestinal helminthes infection, Fasciolosis is widely distributed in tropical and sub-tropical areas where it is recognized as a major source of production losses in domestic ruminants (Hammond and Sewell, 1990; Mage et al., 2002; Fufa Abuna et al., 2010) and one of the major anemia causing helminthes infections in the tropics (Urquhart et al., 1973). In cattle infected either by trypanosomes and/or some of gastrointestinal parasites, anemia is a wellrecognized and inevitable consequence. In tsetse infested areas, anemia has been mainly attributed to trypanosome infections (Morrison et al., 1981). There is however, GI helminthes infection equally potent and highly prevalent anemia causing pathogen that affect the cattle production (Kaufmann and Pfister, 1990; Langridge, 1976). According to Hansen and Perry (1994), infections with some parasite species, particularly Haemonchus but also Bunostomum, Trichuris and Fasciola species can cause anaemia. For instance, in acute haemonchosis and fascioliasis, the pathogenic effect of the parasite is often present before eggs appear in the faeces. Furthermore, in the context of trypanosomosis infection superimposed on GI helminthes infection, Kaufmann et al., (1992) and Urquhart et al., (1990) reported a phenomenon of immune-suppression, reduced prepatent period and increased pathogenecity. 
In Ethiopia, investigations on trypanosomosis and GI helminthes infection have been well addressed as a separate disease. However, the frequent occurrence of concurrent infection of trypanosomosis and GI helminthes infection under field conditions in the tropics is well documented. In addition, Hepworth and Hutchens (2006) described that risk as well as economic loss owing to this concurrent infection in livestock usually remains unobservable due to lack of knowledge and poor awareness level. In the present study area where mixed crop-livestock production system is the main form of agriculture, there has been no information with regard to concurrent trypanosome and GI helminthes infections in cattle. Therefore, the objectives of this study were to determine the prevalence of bovine trypanosomosis and GI helminthes infection in the study area and understand the concurrent infections of both in the context of PCV and EPG.

\section{Materials and Methods}

\section{Study area description}

This study was conducted in Bekelcha Biftu, Kolo Siri, Ambelta and Tuta Peasant Associations of Bedele district located in Illubabor Zone of Oromia region, Southwestern part of Ethiopia from October 2011 to March 2012. Bedele is located $480 \mathrm{kms}$ west of Addis Abeba at an altitude of 2060 metres above sea level (m.a.s.l.). The mean annual rain fall of the area is about $1800 \mathrm{~mm}$ and the mean annual minimum and maximum temperatures are $14.5^{\circ} \mathrm{C}$ and $30.4^{\circ} \mathrm{C}$, respectively. Natural broad leaf forests and grass land cover non-cultivated land in the area. The main farming system in the area is mixed farming and cattle are the most abundant animal species kept in the area (BARDO, 2011).

The area possesses a total population of 102,272 cattle, of which 30,537 are oxen, 25,981 are cows and 16,175 are steers, 17,189 are heifers and 12,390 are calves. The cattle in the area are indigenous East African zebu breeds and are kept under

The area possesses a total population of 102,272 cattle, of which 30,537 are oxen, 25,981 are cows and 16,175 are steers, 17,189 are heifers and 12,390 are calves. The cattle in the area are indigenous East African zebu breeds and are kept under traditional extensive husbandry systems with communal herding (BARDO, 2011). 


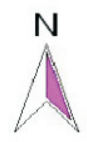

\section{Study Area}

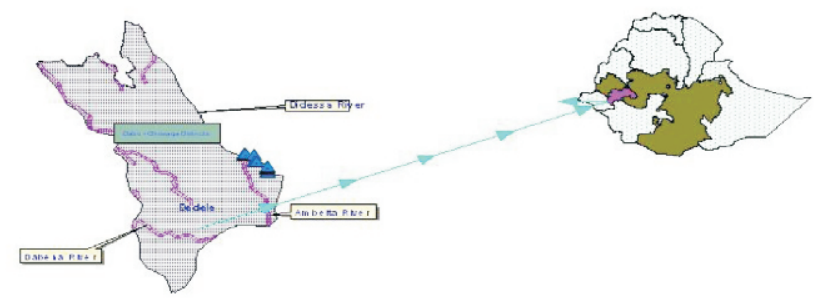

0

60 Kilometers

Source : NTTICO

GIS March, 2012

\section{Study area /Bedelle District/ (Bleeding and feacal sample collection site)}

Study animals and study design

The animals used in this study were indigenous zebu cattle managed under extensive husbandry system. A cross-sectional study design was used to determine the prevalence and concurrent infection of trypanosomosis and GIT helminthes infection in the study area.

\section{Sampling and Sample size determination}

Bedele district and the Peasant associations (PAs) were selected purposively based on information of existence of trypanosomosis from National tsetse and trypanosomosis Investigation and Control Center and ease of access for transportation. Cattle owners in PAs were informed to gather their animals at one point one day ahead of sample collection and simple random sampling technique using lottery method was used to recruit study animals. The sample size required was calculated at $50 \%$ prevalence with level of precision at $5 \%$ and $95 \%$ confidence interval using the formula described in Thrusfield (2005). The prevalence was set to $50 \%$ to increase sample size. 


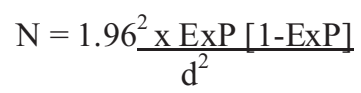

Where:

$\mathrm{N}$ : sample size required

ExP: expected prevalence

d: expected precision

As a result, the required sample size was 384 , but to increase the representativeness of study animals and precision, sample size of 500 animals was considered.

\section{Hematological Examination}

Cattle to be sampled were restrained properly and followed by aseptically preparing areas around ear vein for sampling. The tip of lancet was used to prick ear vein of cattle to be sampled and blood was taken into heparinized haematocrit tubes from the ear vein for diagnosis of trypanosomosis on the spot. Blood samples collected were examined for trypanosomes using the Buffy Coat Technique (BCT) (Murray, et al., 1977). A pair of capillary tubes was filled with blood until three fourth and sealed at one end with sealants. Filled capillary tubes were centrifuged at the speed of 12,000 revolutions per minute (rpm) for five minutes. After centrifugation PCV of each sample was read using micro-haematocrit reader and animals with PCV reading below 24 were considered as anemic. For the presence of trypanosomes the buffy coat-plasma junction was examined under microscope and species was identified based on their characteristic movements.

\section{Coprological Examination}

Faeces of 5-10 grams were collected directly from the rectum of animals sampled for identification of eggs of gastrointestinal helminth using sterile glove in to labeled universal bottles with $10 \%$ formalin as preservative. The well-sealed faecal samples were then transported to Bedele National Tsetse and Trypanosomiasis Investigation and Control Centre (NTTICC) for coprological investigation.

Parasitological examination was done by sedimentation and flotation techniques following the standard procedures to identify eggs of parasitic helminthes. Those faecal samples that were positive for flotation technique were subjected to eggs per gram (EPG) of faeces count using Mc Master egg counting technique and the degree of infestation was categorized as light (50-300), moderate (301-500) and severe (> 500) (Soulsby, 1986; Hansen and Perry, 1994; Urquhart, et al., 1996). 
Data Analysis and Management

Data collected were entered into Microsoft Excel spread sheet and descriptive statistics was applied to calculate the prevalence of trypanosomosis and GI helminthes using SPSS version 16. Mean values of PCV and EPG were determined along with standard error. The Percentages (\%) were used to measure prevalence and chi-square $(\chi 2)$ to measure significance of association among variables considered in this study. In all the analysis, confidence level was held at $95 \%$ and $P$ $<0.05$ was set for significance.

\section{Results}

Prevalence of trypanosome and GIT helminthes infection

Out of the total 500 cattle examined for the occurrence of trypanosomosis $21(4.2 \%)$ of them were found to be positive and the only species identified was $T$. congolense. The overall mean PCV value was $26.7 \pm 3.9$ and it was $26.8 \pm 3.9$ in trypanosome negative animals and $22.9 \pm 3.3$ in trypanosome positive animals.

At least one GIT helminthes infection was detected in 321 (64.2\%) animals examined in this study and there was no statistically significant variation in prevalence among PAs (Table 1). The mean EPG count was 172 \pm 99.6 . Furthermore, of $96(30 \%)$ animals confirmed to be GI helmin thes infection positive by floatation, the degree of infection were light for $97 \%, 2.0 \%$ moderate and $1.0 \%$ were severely infected.

Of detected one or more GI helminthes infections in 321 animals, 166(51.7\%) and 155(48.3) were found in male and female, respectively and the variation was found statistically insignificant $(\mathrm{P}>0.05)$ (Table 1). 
Table 1. Prevalence of single and mixed infection of GI helminthes infection in Bedele district PAs and based on sex.

\begin{tabular}{llllllllll}
\hline \multicolumn{1}{c}{} & & $\begin{array}{l}\text { No. of } \\
\text { animals } \\
\text { exam. } \\
(\mathrm{N}=500)\end{array}$ & $\begin{array}{l}\text { Fasciola } \\
(\%)\end{array}$ & $\begin{array}{l}\text { Paramph } \\
\text { istomum } \\
(\%)\end{array}$ & $\begin{array}{l}\text { Eimeria } \\
(\%)\end{array}$ & $\begin{array}{l}\text { Trichuris } \\
(\%)\end{array}$ & $\begin{array}{l}\text { Trichostrongyle } \\
(\%)\end{array}$ & $\begin{array}{l}\text { *Mixd } \\
\text { infecti } \\
\text { on (\%) }\end{array}$ & \\
\hline PAs & $\begin{array}{l}\text { Bekelcha } \\
\text { biftu }\end{array}$ & 88 & $32(36.4)$ & $11(12.5)$ & $4(4.5)$ & $5(5.7)$ & $7(8)$ & $4(4.5)$ & \\
& Kolo siri & 109 & $41(37.6)$ & $11(10.1)$ & $5(4.6)$ & $6(5.5)$ & $7(6.4)$ & $0(0)$ & $\mathrm{X}^{2}=13.1$ \\
& Ambelta & 82 & $27(33)$ & $8(10)$ & $2(2.4)$ & $2(2.4)$ & $7(8.5)$ & $5(6.1)$ & $\mathrm{p}=0.76$ \\
& Tuta & 221 & $65(29.4)$ & $30(13.6)$ & $9(4.1)$ & $9(4.1)$ & $14(6.3)$ & $10(4.5)$ & \\
\hline Sex & Male & 257 & $88(34.2)$ & $26(10.1)$ & $7(2.7)$ & $12(4.7)$ & $24(9.3)$ & $9(3.5)$ & $\mathrm{X}^{2}=3.33$ \\
& Female & 243 & $77(31.7)$ & $34(14)$ & $13(5.1)$ & $10(4)$ & $11(4.3)$ & $10(4)$ & $\mathrm{P}=0.22$ \\
& & & & & & & & & \\
\hline
\end{tabular}

Age-wise distribution of GI helminthes infection

Of 321 animals detected to harbor one or more GI helminthes, $140(43.6 \%), 179$ $(55.8 \%)$ and $2(0.6 \%)$ were within age category of $<3$ years, $3-9$ years and $>9$ years, respectively and statistically there was insignificant association among age groups (Table 2).

Table 2. Age-wise prevalence of GI helminthes inf ection

\begin{tabular}{|c|c|c|c|c|c|c|c|}
\hline 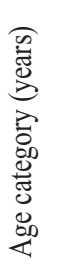 & 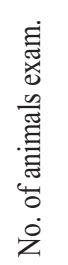 & $\frac{\widehat{a}}{\frac{0}{3}}$ & 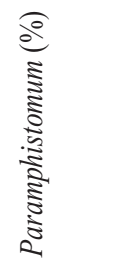 & 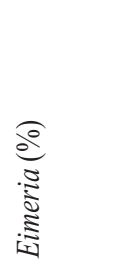 & 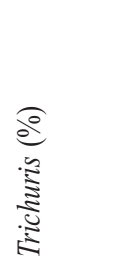 & 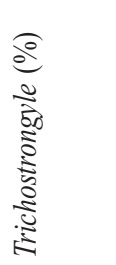 & 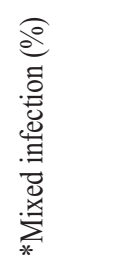 \\
\hline$\leq 3$ & 226 & $64(28.3)$ & $28(12.4)$ & $10(4.4)$ & $13(5.75)$ & $18(8)$ & $7(3.1)$ \\
\hline$>3$ & 274 & 101(36.9) & $32(11.8)$ & $10(3.7)$ & $9(3.3)$ & $17(6.3)$ & $12(4.4)$ \\
\hline Total & 500 & $165(33)$ & $60(12)$ & $20(4)$ & $22(4.4)$ & $35(7)$ & $19(3.8)$ \\
\hline
\end{tabular}

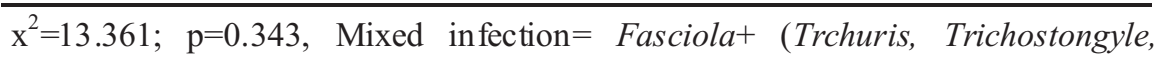
Eimeria); Paramphistomum+ (Trichuris, Trichostrongyle). 
Concurrent infection of trypanosomes and GI helminthes

Trypanosome positive animals (21) were also found to harbor Fasciola (38.1\%), Trichuris (19\%) and Trichostrongyle (19\%) (Table 3) and there was significant association $(\mathrm{P}<0.05)$ between trypanosome and GIT helminthes infections.

Table 3. Cross-tabulation of BCE and Coprological examination

\begin{tabular}{|c|c|c|c|c|c|c|c|c|}
\hline $\mathrm{BCE}$ result & $\begin{array}{l}\text { Fasciola } \\
(\%)\end{array}$ & $\begin{array}{l}\text { Paramphi } \\
\text { stomum } \\
(\%)\end{array}$ & $\begin{array}{l}\text { Eimeria } \\
(\%)\end{array}$ & $\begin{array}{l}\text { Trichuris } \\
(\%)\end{array}$ & $\begin{array}{l}\text { Trichostron } \\
\text { gyle }(\%)\end{array}$ & $\begin{array}{l}\text { *Mixed } \\
\text { infection } \\
(\%)\end{array}$ & $\begin{array}{l}\text { Negative } \\
\text { Helmith } \\
\text { infection } \\
(\%)\end{array}$ & Total \\
\hline $\begin{array}{l}\text { T.congolen } \\
\text { se }\end{array}$ & $8(38.1)$ & $2(9.5)$ & $0(0)$ & $4(19)$ & $4(19)$ & $0(0)$ & $3(14.3)$ & 21 \\
\hline Negative & $157(32.8)$ & $58(8)$ & $20(12.1)$ & $18(4.2)$ & $31(3.8)$ & $19(6.5)$ & $176(36.7)$ & 479 \\
\hline Total & $165(33)$ & $60(12)$ & $20(4)$ & $22(4.4)$ & $35(7)$ & $19(3.8)$ & $179(35.8)$ & 500 \\
\hline
\end{tabular}

$\mathrm{X}^{2}=20.063 ; \mathrm{p}=0.003 ;$ Mixed infection $=$ Fasciolat (Trchuris, Trichostongyle, Eimeria); Paramphistomum+ (Trichuris, Trichostrongyle), BCE = buffy coat examination

Among 321 animals positive for GI helminthes, 18(3.6\%) were found to be positive for both GI helminthes infection and T. congolense (Table 4).

Table 4. PCV and EPG of animals positive for trypanosomosis and GI helminthes

\begin{tabular}{lllll}
\hline No. of animals & BCE & $\begin{array}{l}\text { GI helminthes } \\
\text { infection }\end{array}$ & PCV & EPG \\
\hline 4 & & Trichostrongyle & $22 \pm 3.56$ & $163 \pm 63$ \\
8 & T.congolense & Fasciola & $24.6 \pm 3.6$ & - \\
2 & T.congolense & Paramphistomum & $21 \pm 4.2$ & - \\
4 & T.congolense & Trichuris & $20.5 \pm 2.1$ & $113 \pm 75$ \\
\hline
\end{tabular}

\section{Discussion}

In this study the prevalence of trypanosomosis recorded was $4.2 \%$ and the only species identified was T. congolense. In contrast, Getachew Abebe and Yilma Jobre (1996) reported that $T$. congolense and T.vivax were the most prevalent trypanosomes that infect cattle in the tsetse infested and tsetse free areas of Ethiopia. Their study revealed that in tsetse infested areas of the country, the prevalence of T.congolense was found to be high (58.5\%). Another study by Moti Yohannes et al., (2012) recorded prevalence of 5.8\% T. congolense in Ghibe valley of Ethiopia. However, in areas of East Wollega Zone (Sibu Sire) the respective 
ratios between T.congolense (36\%) and T.vivax (64\%) infections were reported (Shimelis Dagnachew and Sisay Shibeshi, 2011). Their report revealed, the presence of high prevalence of $T$. vivax is an indicator of the importance of mechanically transmitted Trypanosoma in an area where tsetse control program is undertaken. Low prevalence of trypanosomosis recorded in the present study might be attributed to the reduction of tsetse population and other biting flies due to bush clearing for agricultural expansion in the settlement areas.

The mean PCV value of the animals examined in this study was found to be 26.7 \pm 3.9 . The parasitaemic and aparasitaemic animals mean PCV values were $22.86 \pm 3.32$ and $26.84 \pm 3.9$, respectively. In cattle the normal range of PCV value was found to be 24-46 (Blood, et al., 1989). In this context the result confirmed that trypanosome positive animals had lower PCV value. This finding strongly agree with the report of Shimelis Dagnachew and Sisay Shibeshi (2011) who reported mean PCV value of parasitaemic animals as $23 \% \pm 3.7$ and aparasitaemic animals as $26 \pm 3.9$. Moreover, the result is in agreement with the findings of Tone (2008) who reported PCV of $21.84 \%$ and $27 \%$ for cattle positive and negative for trypanosome infection, respectively. This result is also similar with the result obtained by Haile Chernet (1996) and SRVL (2006) who reported PCV values of less than $24 \%$ for $70 \%$ of the parasitaemic animals.

Several authors indicated that in an increase in PCV value, the proportion of positivity of trypanosomosis decreases and hence mean PCV is considered as a good indicator for the health status of a herd in an area endemic to trypanosomosis (Rowlands et al., 2001). In contrast, during trypanosomosis diagnosis lower mean PCV value in parasitaemic and aparasitaemic animals is reported by several authors (Nega Tewelde, 2001; Yohannes Afework, 1998; Leak et al., 1987). They indicated that the resulting low PCV value may not solely be due to trypanosomosis however, the difference in mean PCV between parasitaemic and aparasitaemic animals indicates that trypanosomosis involvement in reducing the PCV values in infected animals. So, other diseases considered to reduce the PCV values of the animals in the study area may include helminthiasis and malnutrition.

The present study also revealed that $64.2 \%$ of cattle examined were found to harbor one or more GIT parasites. This overall prevalence result of parasites infection of cattle in this study was almost in line with the reports of Tesfaye Haile (2006) in dairy cattle of South Wollo (60\%). The major GIT parasites identified in this study were Fasciola species (51.4\%), Paramphistomum species (18.7\%), Eimeria species (6.2\%), Trichuris species (6.9\%), Trichostrongyle (11\%) and 
mixed infection (6\%). In contrast, gastrointestinal parasites identified by Fikru Regassa et al., (2006) in Western Oromia include Ascaris (2.8\%), Eimeria (3.9\%), Strongyles (47\%), Lung worms (0.4\%), Trichuris $(1.6 \%)$ and Tape worms $(0.4 \%)$ According to their report, strongyles and Eimeria were the most prevalent parasites encountered and this difference in the prevalence of gastrointestinal helminthes might be due to different management systems and regions of investigation area.

The mean EPG of GIT parasites regardless of their species was counted to be 172 \pm 99.64 . In contrast Rahman and Sadam (2010) reported the mean EPG count of $516.67 \pm 354.49$ in Chittagong cattle. The present study also revealed that majority of the animals were in light infection (97\%) category, some of them were affected with moderate infection $(2.0 \%)$ and few (1\%) were affected with severe infection. This study almost agrees with the findings of Fikru Regassa et al., (2006) who reported the degree of light infection as $81.3 \%$ in their research work in western Oromia. On the contrary the proportion of animals with moderate infection in this study was by far lower than the reports of Fikru Regassa et al., (2006) who recorded a moderate infection in $13.2 \%$ of the cases among affected animals. But it is inconsistent with reports from eastern Ethiopia (Abebe Wossene and Esayas Gelaye, 2001) that could be explained by the difference in management system. Although the highest prevalence was recorded in Tuta and Kolo Siri PAs, the difference in prevalence was not statistically significant $(\mathrm{p}>0.05)$ across the PAs included in this study.

Sex-wise distribution of GI helminth infection prevalence was seen in this study. Analysis of the results on the basis of single and concomitant diseases revealed that $61.1 \%$ of animals had single and $3.5 \%$ animals had mixed infection while $59.7 \%$ female animals had single and $4.1 \%$ animals were found with mixed types of GI helminthes infections. Nevertheless, this result indicated that sex-wise prevalence helminthes infection was not found to be statistically significant $(\mathrm{p}>0.05)$. This result strongly agrees with the results reported by Fikru Regassa et al., (2006) who found no significant difference in prevalence of the parasites and degree of EPG between male and female subjected to the helminthes infections.

Age was also an important variable considered to see difference in prevalence of GI helminth infection in cattle recruited for this study. Prevalence of $61.6 \%$ and $4.4 \%$ single and mixed GI helminth infection respectively were recorded in age category between 3-9 years in respect of the number of animals examined. Similarly, prevalence of $59 \%$ and $3.1 \%$ single and mixed infections respectively 
were recorded in animals with age groups of $<3$ years. It was observed that GI helminth infection prevalence difference among all age groups considered in this study was not statistically significant $(\mathrm{p}>0.05)$. This may be due to equal exposure of all animals to contaminated pastures with equal chances to get infections. This result disagrees with different authors suggestion (Dunn, 1998; Nwosu, 1996), who stated that adult animals may acquire immunity to the parasites through frequent challenges and expel the ingested parasites before they establish infection.

This study s also strongly focused on concurrent infection of trypanosomsis with GI parasites infection. In the present study, trypanosomosis positive animals (21) were also found to harbor Fasciola species (38.1\%), Trichuris species $(19 \%)$ and Trichostrongyle $(19 \%)$ and there was statistically significant association $(\mathrm{P}<0.05)$ between the two infections. The findings of the present study also revealed that concurrent infection of $T$. congolense and Fasciola species is the most prevalent form of co-infection in cattle within study areas. This observation basically agrees with the results of Kaufmann et al., (1992) and Dwinger et al., (1994) who disclosed an increased pathogenicity when helminthosis is superimposed on Trypanosoma infections. Furthermore, in our study marked anemia (lower PCV value) was recorded in animals with mixed infections of trypanosome and helminthosis. This finding agrees with the report of anemia in mixed infections of T.congolense and H.contortus in experimentaly infected sheep (Kaufmann et al., 1992). Although lower mean EPG counts were obtained in animals concurrently infected by both infections compared with the overall mean EPG counts in this study, a previous study carried out to assess the effects of concurrent T.congolense and H.contortus infections in N'Dama cattle showed a significant rise in egg output in animals harboring both infections and attributed the finding to the immune-suppressive effect of T.congolense infection (Kaufmann et al., 1992).

In conclusion, the present study revealed that in trypanosomosis edemic areas, GI helminthes infection should also be given due attention for effective and efficient livestock production. Any attempts in the control of the two diseases using antiheminthic treatment must consider the possible coexistence of both infections for possible adjustment of the treatment accordingly. Moreover, management decisions aimed at strategic helminthes control especially in small scale farming practice where diagnosis is mostly by physical clinical examination and epidemiology of parasites; need to address the possibility of concurrent infections to save the losses in advance. 


\section{References}

Abebe, G. and Jobre, Y., 1996. Trypanosomosis: A threat to cattle production in Ethiopia. Rev. Med. Vet.147, 897-902.

Abebe, G., 2005. Trypanosomosis in Ethiopia, Review article. Ethiop. J. Biol. Sci., 4, 75-121.

Abunna, F., Asfaw, L., Megersa, B., Regassa, A., 2010. Bovine fasciolosis: coprological, abatto ir survey and its economic impact due to liver condemnation at Soddo municipal abattoir, Southern Ethiopia. Trop. Anim. Hlth. Prod., 42, 289-292.

Afework, Y., 1998. Field investigation on the appearance of drug resistant population of trypanosomes in Metekel District, North-West Ethiopia. Msc thesis, Addis Ababa University and Freiuniverstat Berlin, Faculty of veterinary medicine, Ethiopia.

BARDO, 2011: Bedelle Agricultural and Rural Development Office.

Blood, D.C., Radostits, O.M. and Henderson, J.A., 1989. Disease caused by protozoa. A text book of the disease of cattle, pigs, goats and horses. $7^{\text {th }}$ ed. Oxford: ELBS, pp. 1012 1015 .

CFSPH (2009). African animal trypanosomiasis. The Center for Food Security and Public Health (CFSPH), Iowa State University. www.cfsph.iastate.edu.

Chernet, H., 1996. Bovine trypanosomosis in North Omo prevalence and assessment of drug efficacy. DVM Thesis. AAU, FVM, Debre Zeit, Ethiopia.

Dagnachew, S., and Shebeshi, S., 2011. Prevalence and vector distributions of bovine trypanosomosis in control (Sibu Sire) and no control (Guto Gida) districts bordering upper Anger valley of East Wollega Zone, Western Ethiopia. Ethiop. Vet. J., 15: 77-86.

Dunn, A.M., 1998. Veterinary Helminthology. $2^{\text {nd }}$ ed. London Willian Heinemann Medical books, pp. 253-255.

Dwinger, R.H., Agyemang, K., Kaufmann, J., Grieve, A.S. and BAH, M.L., 1994. Effects of Trypanosome and helminthes infections on health and production parameters of village N'Dama cattle in The Gambia. Vet. Parasitol., 54, 353-356.

Food and Agriculture Organization (FAO), 2002. Program Against African Trypanosomiasis (PAAT). Twenty second Regional Conference for Africa, Cairo, Egypt, 4-8 February 2002.

Haile, T., 2006. Ovine and bovine helminthiasis in Kelala (S.Wollo), Ethiopia Veterinary Association Proceedings of the $12^{\text {th }}$ conference, Addis Ababa, Ethiopia, June 30-34.

.Hammond, J. A. and Sewell,M.M.H.,1990. Diseases caused by helminths, In: M.M.H., Sewell and D.W. Brocklesdy (eds), Hand book of animal diseases in the tropics, $4^{\text {th }}$ edition (CTVM, Edinburgh University) 119-123. 
Hansen, J. and Perry B., 1994. The Epidemiology, Diagnosis and Control of Helminth Parasites of Ruminants.A handbook. $2^{\text {nd }}$ edition. ILRAD (International Laboratory for Research on Animal Diseases), Nairobi, Kenya, Pp. 171.

Hepworth, K., Hutchens, T., 2006. Animal science managing internal parasitism in Sheep and goats. Purdue Extension, College of Agriculture, University Kentu. http://www.ces.purdue Edu/extmedia/AS/AS-573-W.

Kaufmann J., Dwinger R.H., Hallebeek A., van dijk B. and Pfister K., 1992. The interaction of Trypanosome congolense and Haemonchus contortus infections in trypanotolerant N'Dama cattle. Vet. Parasitol., 43, 157-170.

Kaufmann, J. and Pfister, K., 1990. The seasonal epidemiology of gasterointestinal nematodes in N'Dama cattle in Gambia. Vet. Parasitol., 37, 45-54.

Langridge, W. P., 1976. Tsetse and Trypanosomosis Survey of Ethiopia. Ministry of Overseas Development, UK and Ministry of Agriculture, Ethiopia, pp. 1-40.

Leak, S. K. A., Woume, K. A., Collardelle, C., Duffera, W., Feron, A., Mulingo, M, Tikubet, G., Toure, M., and Yangari, G., 1987. Determination of tsetse challenge and its relationship with trypanosomosis prevalence. Livestock production in tsetse infested areas of A frica, ATLN, Nairobi, Kenya, pp. 43-52.

Mage, C., Bourgne, H., Toullein, J, M., Ronde Laud, D. and Dreyfuss, G., 2002. Fasciola hepatica and paramphistomum doubney: changes in prevalence of natural infections in cattle and in Lymnea truncatula from central France over 12 years. Vet. Res., 33,439-447.

Morrison W.L., Murray M., and Mcintyre W.I.M., 1981. Bovin trypanosmiasis in Diseses of Cattle in the Tropics. M. Ristic and I. McIntyre (Ed) Martinus Nyhoff Publishers, the Hague, pp. 469-497.

Murray, M., Murray, P.K and Mc Intyre, W. I. M., 1977. An improved parasitological technique for the diagnosis of A frican trypanosomosis. Trans. R. Soc. Trop. Med. Hyg., 71,325-326.

Nwosu, C.O., Ogurrinade, A.F., and Fagbeni, B.O., 1996. Prevalence and seasonal changes in the gastrointestinal helminthes of Nigeria goats. J. Helminthol, 70, 329-333.

Radostits, D. M., Gray, C. C., Blood, D. C. and Hinchelift, K. W., 2000. Veterinary medicine: A Textbook of the diseases of cattle, sheep, pig, goat and horses. $9^{\text {th }}$ Ed. W.B Saunders Company Ltd. London, pp. 1329-1337. 
Rahman, M.M. and Sadam, M.A., 2010.Prevalence of subclinical gastro-intestinal parasitosis and their effects on milk production with therapeutic management in red Chittagong cattle. Bangl. J. Vet. Med., 8, 11-16.

Regassa, F., Teshale, S., Reta, D. and Yosef, K., 2006. Epidemiology of Gastrointestinal Parasites of Ruminants in Western Oromia, Ethiopia. Int. J. App. Res. Vet. Med., 4, 51-57

Rowlands, G. J., Leak, S. G. A. Peregrine, A. S., Nagda, S. M., Mulatu, W. and d'Ieteren, G. D. M., 2001.The incidence of new and the prevalence of recurrent trypanosome infection in cattle in South-West Ethiopia exposed to a high challenge with drug resistant parasite. Acta. trop., 79, 149-163.

Soulsby, E.J.L., 1986. Helminthes, Arthropods and Protozoa of Domesticated Animals. $7^{\text {th }}$ edition.London, UK, Bailliere, Tindall.

SRVL, 2006. Southern Regional Veterinary Laboratory. Annual reports, Soddo, Ethiopia

Tewolde, N., 2001. Study on the occurrence of drug resistant trypanosomes in cattle in the farming in tsetse control areas (FITCA) project in Western Ethiopia. MSc thesis, Addis Ababa University, Faculty of veterinary medicine, Ethiopia.

Thrusfield, M.V., 2005.Veterinary Epidemiology. $3^{\text {rd }}$ edition, Blackwell Publishing Professional, USA, pp 183.

Tone, P., 2008. Prevalence of bovine trypanosomosis in selected sites of Southern Region of Ethiopia. DVM Thesis, Addis Ababa University, Faculty of veterinary medicine, Ethiopia.

Urquhart GM, Armour J, Duncan J.L., Dunn A.M., and Jennings, F.W., 1996. Veterinary Parasitology. $2^{\text {nd }}$ ed. Blackwell science, UK.

Urquhart GM, Armour J, Duncan JL, Dunn AM, and Jennings F.W., 1994. Veterinary Parasitology. $1^{\text {st }}$ ed ition.Singapore, Longmann.

Urquhart, G.M., Murray M., Murray P. K., Jennings F.W. and Bate, E., 1973. Immunosuppressant in Trypanosoma brucei infections in rats and mice. Trans Roy. Soc. Trop. Med., 67, 528-535.

Vercruysse, J. and Claerebout, E., 2001. Treatment versus non treatment of helminth infections in cattle defining the thresh holds. Vet. Parasitol.98, 195-214.

Wossene, A. and Gelaye, E., 2001. Survey on ovine and caprine gastro-intestinal helminthosis in eastern part of Ethiopia during the dry season of the year. Rev. Vet. Med., 152, 379-384.

Yohannes, M., Regassa, F., Van Den Abbeele J., Büscher P., Van den Bossche P. Duchateau L. and Delespaux V., 2012. Vet. Parasitol., 189,197- 203. 